\title{
A LEMMA FROM NOWHERE
}

\author{
IMOGEN DICKIE \\ University of St Andrews \\ id54@st-andrews.ac.uk
}

SUMMARY: This paper uses cases involving empty singular terms (on the one hand, cases of what I call "accidental aboutness-failure"; on the other, cases involving proper names occurring in fictions) to argue for a claim about the goal of ordinary belief-forming activity, and shows how this claim generates new foundations for the theory of reference.

KEY WORDS: empty singular terms, fictional names, theory of reference, belief formation, aboutness

RESUMEN: Este artículo usa casos que involucran términos singulares vacíos (por una parte, casos de lo que llamo "acercaidad-fallida accidental"; por otra parte, casos que involucran nombres propios que aparecen en ficción) para argumentar a favor de una postura acerca de la meta de la actividad ordinaria de formar creencias, y muestra cómo esta postura genera nuevos fundamentos para la teoría de la referencia.

PALABRAS CLAVE: términos singulares vacíos, nombres de ficción, teoría de la referencia, formación de creencias, acercaidad

\section{Introduction}

This paper uses our understanding of empty singular terms to argue for a claim (hereafter "the lemma") which will turn out to have farreaching consequences.

The lemma concerns what I shall call "ordinary" belief-forming activity: the formation, in response to perception and testimony, of the beliefs we standardly express using ordinary (non-scientific and non-philosophical) language. Here are two cases to illustrate activity of this kind:

Case 1 You are in an ordinary situation where you have no reason to doubt the deliverances of perception. Looking at an orange on the table in front of you, you form, by uptake from perception, a body of beliefs you would express using sentences containing "that": "That is rolling" you think; "That is orange"; "That is spherical"; "That is about to fall". 
Case 2 You have not heard the name "Aneurin Bevan" before. Somebody begins to explain who Bevan was: "Aneurin Bevan was a British Labour Party politician. He was a long-standing member of parliament, and a cabinet minister in the 1940s and 50s. He was instrumental in the foundation of Britain's National Health Service." Nothing about the situation leads you to doubt your informant's reliability. You take the utterances at face value, forming a body of beliefs you would use the name "Aneurin Bevan" to express.

And here is the lemma, with clarification to follow:

The lemma - Part of the aim of ordinary belief-forming activity is to secure and maintain aboutness relations with particular things.

In treating ordinary belief-formation as an "activity" and, therefore, as having an "aim", the lemma joins the long tradition of recognising ordinary belief formation as something we $d o$ - as a response we make to input from perception and testimony, as opposed to something that merely happens to us. It is important not to confound the claim that ordinary belief formation is something we do with a stronger claim which I take to be obviously false: the claim that it is something we choose to do. There is a once-widespread view of the difference between things we do and things which happen to us which collapses the first claim into the second. This is the view that the things we do just are the things with respect to the doing of which we have a choice, so that "S performed action A (or engaged in A-ing activity)" entails "S could have done otherwise". ${ }^{1}$ But a now more widespread alternative view rejects this "could have done otherwise" criterion. According to the alternative view, what is distinctive of action or activity is that these are guided by motivational states of the subject, while mere happenings are not. ${ }^{2}$ Suppose you intend to pick up the glass and have a drink. According to the "action only if guidance" view, what makes picking up the glass an action of yours

${ }^{1}$ One pathway to this view is the "causalist" claim that actions are distinguished from happenings by their causes, together with the view that the causes distinctive of actions are choices made by the subject. Compare Davidson 1980a and 1980b.

${ }^{2}$ The move to this kind of model is explicit in Frankfurt 1978. To avoid a threat of circularity - actions are guided by motivational states; motivational states are states that guide actions - a full-dress presentation of this view must say more about the notion of guidance. The standard move is to appeal to goal representation; monitoring of current status relative to goal; and adjustments which are dependent on these two factors. Compare Frankfurt 1978, p. 74. I say a little more about this at Dickie 2015, pp. 96-98. 
is that the movements you make as you reach out your hand are guided by your intention: your intention selects a train of movement which will generate its fulfilment unless your situation is unlucky. This is the view I shall assume in what follows. So the lemma is to be read as saying that ordinary belief-forming activity - the kind of activity that generates your beliefs in Cases 1 and 2- unfolds as it does partly because it is guided by a motivational state directed towards securing and maintaining aboutness relations.

Now, the suggestion that ordinary belief-forming activities are guided by intentions is as implausible as the suggestion that they are activities in which we choose to engage. But it is a familiar part of folk psychology that there are "motivational states" — states whose functional role is to generate actions which meet their fulfilment conditions - other than intentions. An intention is a motivational state which is also an attitude to a proposition: $\mathrm{S}$ intends to bring it about that p. But many of our motivational states are not propositional attitudes. I shall call non-propositional - non-conceptualmotivational states "needs". One way to think of the distinction between intentions and needs is in terms of whether the subject of the state must have the conceptual sophistication to understand what it would take to fulfil it. In the case of intentions, the answer is "yes". You cannot have an intention whose fulfilment conditions you lack the sophistication to specify. (If you do not grasp the concept of fairness, you cannot intend to divide the spoils fairly.) In the case of "needs" the answer is "no": my dog is motivated by the need to avoid loneliness, but presumably does not grasp the concepts of loneliness or avoidance. ${ }^{3}$ The lemma deals in needs rather than intentions. The suggestion is that we need to tune in on objects as subject matter for thought in something like the way we need to avoid hunger and cold, and feel secure, and avoid loneliness.

Note that there is no suggestion that aboutness is either the sole or a fundamental aim of ordinary belief-forming activity. To say that part of what we are aiming for is representation of particular objects is also to allow that part of what we are aiming for is a good-enough representation of the-world-in-general for practical purposes. And the lemma is compatible with all of the following: ordinary belief-forming activity also aims at truth; it also aims at knowledge; it also aims at the delivery of representations which will enable reliable fulfilment

\footnotetext{
${ }^{3}$ The distinction between conceptual and non-conceptual motivational states (intentions and needs) parallels the distinction between conceptual and non-conceptual representational states as drawn in Peacocke 1992, ch. 3.
} 
of the subject's practical goals; it aims at aboutness only as a means to one or more of these other ends. ${ }^{4}$

Note also that we should expect examination of cases involving empty names to yield substantial illumination in the exploration of ordinary belief-forming activity. Some of these cases involve failed attempts at this activity. Others involve mere pretence at it. And if you want to give a full characterisation of an activity - what its aim is; what is required for its success; whether it can be partially successful; what it takes to be a competent practitioner; and so onexamination of failures and episodes of pretending will play an ineliminable role. So one way to think of the spirit of what follows is this. It is tempting to assume that examination of aboutness-failure for ordinary beliefs, and emptiness for ordinary singular terms, belongs at a late stage in inquiry into ordinary thought and speech - to treat aboutness-failure and emptiness as providing puzzles against which a proposal developed by looking at "good" cases can be tested and honed. But if we keep sight of the fact that ordinary beliefformation is an activity, this temptation vanishes: rather than leaving cases of aboutness-failure and emptiness until last, we should look at them right at the beginning, to see what might be learned about the activity from cases where it does not succeed, or where we pursue it in the scope of pretence, in isolation from real-world pressures.

The next two sections of the paper use cases involving empty singular terms to argue for the lemma. The argument in section 2 takes off from cases involving what I shall call "accidental aboutness failure"; the argument in section 3 from cases involving proper names in fiction. Section 4 establishes one central consequence: given the lemma, we can argue for a new approach to explaining how ordinary thought and speech lock onto their subject matters. Section 5 shows how the proposal of section 4 explains an overlooked aspect of our engagement with fiction.

But before beginning the main discussion I want to consolidate what the lemma says by considering the kind of view you might hold if you deny it.

One option here is to deny that ordinary belief formation is, as I have supposed, an activity with an aim. But to keep the discussion to manageable length I shall focus on lemma-denying views which allow this background claim. These are views according to which ordinary belief-forming activity aims at ends which do not include

\footnotetext{
${ }^{4}$ This last clause is intended to allow for the possibility raised in Heck 2017 that the need for aboutness might be "emergent" from other motivational states.
} 
aboutness relations to objects. Any such position must allow that the information-processing that generates our ordinary beliefs - uptake from perception; uptake from testimony - does seem to involve looking for objects. For example, it is widely agreed that formation of perceptual demonstrative beliefs - the beliefs standardly formed by uptake from perception, and expressed using demonstratives like "this" and "that" - requires an attentional perceptual channel which at least seems to the subject to be locked to a particular thing. ${ }^{5}$ In Case 1, you do not just stare unfocusedly into the distance and form the beliefs you would express by saying "That is round; it's orange...". Formation of perceptual demonstrative beliefs requires a perceptual experience that registers as an instance of attention to an object. Similarly, it is widely agreed that following what someone is saying involves keeping track of what linguists call "discourse referents"6 -bundling together utterances as delivering information about the same thing, as illustrated by Case 2. So the question becomes this: How might we accommodate the fact that the information-processing which underpins ordinary belief-forming activity is looking for objects, while denying that finding objects is part of the activity"s aim?

Here are four possibilities. ${ }^{7}$

First lemma-denying view The aim of ordinary belief-forming activity is to generate a right account of the distribution of properties in the world - something like a map showing which properties are instantiated in which regions. Forming new ordinary beliefs is a matter of updating the map. As it happens, much of the information we use in updating the map arrives in object-shaped bundles: perception and language-understanding both deliver streams of information not just as to which properties are instantiated, but as to which are co-instantiated. But the object-shaped bundling is merely a feature of our information-delivery mechanisms. Formation of ordinary beliefs involves unpacking bundles and using the information they

${ }^{5}$ This fact received its first major exploration in Campbell 2002. Note that the claim applies to the "standard" or "usual" path to formation of "that" beliefs in response to perception - the path illustrated by Case 1. Obviously there are cases where we form beliefs which we would express using "that" on the basis of perception which do not belong to the class of perceptual demonstrative beliefs defined as associated with this standard path.

${ }^{6}$ For a linguist's introduction, see Roberts 2004. For a recent philosophical treatment see Cumming 2014.

${ }^{7}$ The first three of these are intended as different ways Stalnaker's view (Stalnaker 1984) that belief-forming activity aims at narrowing the range of live possibilities might be combined with explicit rejection of the lemma. 
contain to update the map of the distribution of properties in the environment. Since the aim of ordinary belief-forming activity is to get the distribution of properties right, whether the activity succeeds depends on whether it gets this distribution right, not on whether it gets objects right: it might succeed even though there are no ordinary objects at all.

Second lemma-denying view The aim of ordinary belief-forming activity is to generate a right account of the distribution of properties in the world. (Again, think of the kind of account we are after as a map... ) Treating various oft-encountered patterns in perception and testimony as putting us in contact with particular things is a form of shortcut which enables us to fill in the map much more efficiently than would be possible otherwise. But the aim of ordinary beliefformation is to be characterised in terms of the map of property distribution, not the shortcuts used to generate it. Success or failure depends on whether the map gets this distribution right. ${ }^{8}$

Third lemma-denying view The aim of ordinary belief-forming activity is to generate a representation of the distribution of properties in the world (a map...). The information in this map is then accessed for practical purposes. As it happens, most of our practical purposes are object-shaped: pick up the glass; sit on the chair; and so on. So, most of the time, when we access information, it is not just instantiation information but co-instantiation information -information that we describe from a pre-theoretic view as "about" various particular things. But the fact that this is the information we most commonly access is a fact aside from the aim of belief-forming activity itself: the guidance mechanism for ordinary belief-forming activity is directed towards getting the world's distribution of properties right; whether the activity succeeds depends on whether this aim is fulfilled. ${ }^{9}$

Fourth lemma-denying view The securing and maintaining of aboutness relations is not part of the aim of ordinary belief-forming activity but a precondition of this activity. For example, in the perceptual demonstrative case, the aboutness-fixing relation is perceptual attention to an object. This relation enables the subject to engage

\footnotetext{
${ }^{8}$ Compare the status of transfinite numbers in Hilbert's formalism - Hilbert 1983.

${ }^{9}$ The distinction between what is believed and what is "accessed" is central to Stalnaker's solution to the "problem of logical omniscience" as it arises in his framework — Stalnaker 1991, 1999.
} 
in ordinary belief-forming activity - an activity whose aim is to get the attended object's properties right. If you are not attending to an object (if there is no underpinning aboutness relation) you are not genuinely engaged in ordinary belief-forming activity at all. ${ }^{10}$

With this contrast-class in place, let us return to the issue at hand. The lemma assigns aboutness relations a specific role in accounts of why ordinary belief formation proceeds as it does. It says that ordinary belief formation proceeds as it does partly because it is an activity directed towards locking on to particular objects as subject matters of thought. We have seen that there are coherent-seeming ways to deny this claim while acknowledging that object-detection plays a central role in the information-processing that generates ordinary beliefs. So why should the lemma be accepted? And if it is accepted, what more might follow?

\section{The Argument from Accidental Emptiness}

This section argues for the lemma from cases of what I shall call "accidental emptiness". Here are two cases of this kind:

Case $3-A$ "that"-thought based on a perceptual link with a nonobject

You are having an experience indistinguishable by you from an experience of a rectangular thing in the middle distance. You have no reason not to take your experience at face value. You form the belief you would express by saying "That is rectangular". In fact, your experience as of something rectangular is caused by a freak combination of a speck on your glasses, a far-off tree, and a building on the horizon.

\section{Case 4- "David Agnew"}

1970s BBC regulations forbad assignment of a scriptwriting credit to anyone other than a show's initial scriptwriters. So a last-minute change by someone outside this group could not be credited to

${ }^{10}$ I take this to be part of the view of perceptual demonstrative thought in Campbell 2002. Campbell argues that conscious perceptual attention to an object both "defines the target" for belief-forming and action-generating informationprocessing (providing the standards which must be met if the information-processing is to go right) and guides the information-processing to meet these standards. This is treating the relation that secures aboutness (conscious perceptual attention) as a precondition for the information-processing that underlies ordinary belief-forming activity, so as a precondition for the activity itself. 
the person who made it. Instead, the fact that such a change had been made would be indicated by adding "David Agnew" - a name introduced for this purpose - to the list of contributors to the script, regardless of the fact that many different people made such lastminute contributions. Seeing "David Agnew" appear repeatedly in $\mathrm{BBC}$ credits from this era, and ignorant of the story behind the name, you end up with a range of beliefs you would express by saying things like "David Agnew could turn his hand to either comedy or drama"; "He preferred comedy"; "He worked on nature programmes in 1976 and 78"; "He worked in children's television in 1975".

In each of these cases, you have what you treat as a body of beliefs about a single ordinary individual, expressible using an ordinary singular term. But the beliefs in Case 3 are about nothing, and those in Case 4 about nobody: "this" as you use it in Case 3 and "David Agnew" as it occurs in Case 4 are empty singular terms.

The argument of this section depends on a claim relating accidental emptiness cases and ordinary belief-forming activity: the claim that these cases are failed attempts at this activity. If this claim is accepted, we should expect to learn something about the aim of ordinary belief-formation from examination of Cases 3 and 4 -if you want to characterise the goal of an activity, one consideration is what counts as a failed attempt. But the claim cannot simply be taken for granted. The fourth lemma-denying view rejects it. (On this view, aboutness is a precondition for ordinary belief-forming activity; Cases 3 and 4 do not even count as failed attempts.) And, though here the situation is subtler, each of the other lemma-denying views might reject the claim as well. (The most obvious suggestion is that, in at least some accidental emptiness cases, the subject is still moving towards a right account of how properties are distributed in the world: if the aim of ordinary belief formation is getting the world's distribution of properties right, accidental emptiness need not spell failure.)

To see why the claim should be accepted, let us break it into its constituent parts. The claim is a conjunction: Accidental emptiness cases are attempts at ordinary belief formation; and they are failed attempts. So we have the following:

First conjunct - accidental emptiness cases are attempts at ordinary belief formation. (Whatever it is that you succeed in doing when you form beliefs by uptake from perception and testimony as in Cases 1 and 2, you are attempting to do in Cases 3 and 4.) 
Second conjunct - accidental emptiness cases involve failure with respect to the goal of ordinary belief formation: whatever this goal is, Cases 3 and 4 do not fulfil it.

I shall provide an initial case for each in turn.

To see the initial case for the first conjunct, consider a parallel. Suppose that Andy Murray goes to serve at tennis. He tosses the ball, swings his racket, and so on, doing these things with all the strength and precision you would expect from a three-time major championship winner (Andy won Wimbledon in 2013 and 16, and the US Open in 2012). However, the ball is not actually a tennis ball: it is a cleverly engineered joke-ball which gives Andy sensory feedback indistinguishable from that involved in interactions with an ordinary tennis ball, until the moment when the ball is hit, when it collapses like a deflated balloon and falls to the ground. Did Andy attempt to serve? Surely he did. The world conspired against him, so that his attempt failed. But as he tossed and struck the non-tennis-ball, his actions were guided by his motivational states in the same way as they are guided in "good" cases: cases where the serve goes well. We can imagine the joke tennis ball deployed very occasionally in high level tennis to try the nerves of participants and add to the spectacle: "Andy struck that beautifully", says the commentator "a very nice attempt at serve. Unfortunately he was playing the joker so the point doesn't count and he'll have to try again." The first conjunct is treating Cases 3 and 4 in this same way: you are responding to perceptual feedback and to testimony in the same ways you respond in "good" cases of ordinary belief formation, attempting to do what you do in these good cases, but the world conspires against you and your attempt does not succeed. ${ }^{11}$

To see the initial case for the second conjunct, consider how you would respond to the discovery that you were in a Case 3 or 4 situation. The usual response would be abandonment of the body of "that" or "David Agnew" beliefs, and the attempt to excise any conclusions drawn from them: you would scrub the beliefs you

\footnotetext{
${ }^{11}$ Note that the criterion in the text entails that cases where you have hallucinations indiscriminable by you from perceptual or testimonial input are not cases where there is a failed attempt at ordinary belief-formation: hallucination-based "bad" cases do not involve responding to perceptual input or testimony the same way as you respond in good cases. It also remains open to say that there is a clear metaphysical difference between the "good" cases and Cases 3 and 4. In "good" cases you stand in "subject is thinking about object" relations to the individuals your thoughts are about. In Cases 3 and 4 you do not.
} 
would have expressed by saying "That is rectangular" or "David Agnew was an old Etonian..." from your ordinary account of the world. You might continue with the activity of maintaining a body of beliefs by uptake from the defective perceptual or testimony channel, but this would require activation of a new motivational state. For example, you might use the information delivered by the defective perceptual channel as a basis for a pretence ("Let's pretend that there's something there. Look-, it's moving to the left..."). Or you might use the distribution of "David Agnew" credits to draw conclusions about 1970s BBC scriptwriting culture ("Comedy was more open to prone to last-minute additions than other genres", and so on). What you cannot do, without incoherence, is continue forming "that" and "David Agnew" beliefs which you incorporate into your ordinary account of the world - the account built up from beliefs formed in cases where ordinary belief-formation succeeds.

There is room for further discussion on each of these points. But for present purposes I shall take the initial cases for the conjuncts to be good enough to be getting on with, and assume the conjunction: accidental emptiness cases are both attempts and failed attempts at ordinary belief-formation. The first argument for the lemma is generated by this conjunction together with a principle connecting the conditions for an attempt at an activity; the conditions for a successful attempt; and the activity's goal:

1 The aboutness of the resulting beliefs is not required for attempts at ordinary belief formation. [From the first conjunct.]

2 The aboutness of the resulting beliefs is required for successful attempts at ordinary belief formation. [From the second conjunct.]

3 If generation of $X$ is required for success at an activity, but not for a mere attempt, then generation of $X$ is part of the goal of the activity.

So

4 The aboutness of the resulting beliefs is part of the goal of ordinary belief formation. [From 1, 2, 3]

The argument is valid. To complete this defence of the lemma, it remains to establish $\mathbf{3}$.

To reach this destination, let us stay with Andy and start at the very abstract. Suppose we are watching Andy do his thing. We might classify his behaviours with respect to the goal "play such-and-such 
shot" as follows: no attempt; attempt and succeed; attempt and fail. All instances of either "attempt and succeed" or "attempt and fail" will have various "background" conditions and "results generated" conditions in common. For example, Andy is awake and Andy is not paralysed are among the background conditions; Andy's racket at least comes close to making contact with the ball might be a result generated. (Obviously it would be very hard to characterise either the background conditions or the "results generated" conditions fully.) Within the class of attempts, there are successes and failures, distinguishable primarily by what they generate, but perhaps also by some of their background conditions (it may be that there are background conditions above and beyond those for making an attempt which are required for success).

Now suppose we set aside background conditions, focus just on what is generated, and ask about the connection between the goal of an activity, what is generated by any recognisable attempt at the activity, and what must be generated by attempts that succeed. We should expect some such connection. A success is an attempt which fulfils the goal. So we at least have (i):

(i) If generation of $\mathrm{X}$ is part of the goal, necessarily, $\mathrm{X}$ is generated in every successful attempt.

But we do not have the converse, (ii):

(ii) If, necessarily, $\mathrm{X}$ is generated in every successful attempt, generation of $\mathrm{X}$ is part of the goal.

(ii) is false because it fails to distinguish what we are aiming for from what must be generated by an action if it is even to count as an attempt. Suppose that $\mathrm{S}$ aims to pass the exam. To count as making an attempt, $\mathrm{S}$ must cover at least (let us say, without supposing a sharp cutoff) four pages of the exam booklet. But covering n-number of pages is not part of S's aim.

To accommodate this point, let us make a preliminary move to (iii) (preliminary because further tweaking is going to be required):

(iii) If, necessarily, $\mathrm{X}$ is generated in every successful attempt, but $\mathrm{X}$ need not be generated by every attempt; generation of $\mathrm{X}$ is part of the goal.

Unlike (ii), (iii) allows that there may be results which must be generated by every attempt — successful or not - but which are not 
part of the goal. It also allows that there are cases where a result which must also be generated by every attempt does figure as part of the goal. Surely I do not count as genuinely having attempted to shelve my books if I have not put even one book on a shelf. But if I aim to put all my books on the shelves, putting at least one book on a shelf is part of my goal. (iii) allows for this because it states only a necessary condition for generation of a result to be part of the goal: it says that if $\mathrm{X}$ meets the condition must be generated in every success but not every attempt, then $\mathrm{X}$ is part of the goal. It leaves open the possibility that some elements of the goal do not meet this condition.

But as it stands (iii) is open to an obvious form of counterexample. Suppose I intend to shelve my books alphabetically. And suppose the last book alphabetically has a blue cover, though I am not aware of this. Then a successful attempt will be an attempt which places a blue book in the last place. A mere attempt need not meet this condition (I might count as trying to shelve the books alphabetically but get things a bit wrong). But placing a blue book last is not part of the aim of my book-shelving activity. ${ }^{12}$

To block counterexamples like this, (iii) must be amended to recognise that it is not just the necessary connection itself that is relevant to identifying components of the goal, but the basis for the necessity. Counterexamples to (iii) arise when generation of $\mathrm{X}$ is a necessary accompaniment to goal-fulfilment and not to a mere attempt, but generation of $\mathrm{X}$ is nothing to do with what makes the attempt count as successful. So what we want is actually something like (iv):

(iv) If $\mathrm{X}$ is a result which must be generated by an attempt in order for the attempt to count as a success, but need not be generated for the subject to count as having made an attempt, $\mathrm{X}$ is part of the goal.

$\mathbf{3}$ in the argument is a compressed version of this claim: (iv) unpacks the notion of a "requirement" that $\mathbf{3}$ contains.

Is there still a gap here through which a counterexample might squeeze?

For the case where the goal-representing state is an intention, this matter is vexed. This is the territory of "collateral damage" excuses. If you intend to win the race, might you nevertheless not intend to

${ }^{12}$ Compare Anscombe 1957, §23. 
inflict failure on the other participants? Maybe this is possible. It is generally held that intending to A requires believing that you will A. ${ }^{13}$ Suppose that all your focus in a race is on crossing the line first, to the extent that you do not regard the bodies in the other lanes as people capable of having failure inflicted upon them. Then you might intend to win without intending to inflict failure. If so, the inflicting of failure on other participants is not part of your goal, even though it meets the condition at (iv).

However, the possibility of a counterexample here comes from a special fact about intentions: if you intend to A you believe that you will A. And we have already noted that the motivational state driving ordinary belief-forming activity is not an intention. We do not intend to form beliefs in response to perception and testimony then go ahead and form them. Rather, we just do form beliefs in response to perception and testimony, and our doing so counts as an activity because it is guided by a non-conceptual motivational state -what I have called a "need".

Now consider how a counterexample to (iv) might look in cases where the motivational state is a need. Consider first the structure of guidance-by-need systems. Schematically, these systems involve representation of a goal-state; monitoring of current status for distance from the goal state; and modulation of behaviour to close the gap between goal-state and current status. ${ }^{14}$ The goal state is identifiable by its functional role. The goal-state of the system just is the state around which the "checking for status" and "modulation of behaviour" parts of the cycle revolve; the need is a need for X iff the guidance system involves checking actual status against $\mathrm{X}$ and making adjustments which will bring actual status in line with $\mathrm{X}$ unless the situation is unlucky. Where the motivational state is a need, there might be cases where success requires generation of $\mathrm{X}$ even though the system is not checking for $\mathrm{X}$. But these will be cases where generation of $\mathrm{X}$ is a requirement on checking for $\mathrm{X}$ or modulating behaviour towards it - that is, $\mathrm{X}$ is a requirement on attempts. If $\mathrm{X}$ is not a requirement on attempts (the system does not need to generate $\mathrm{X}$ in order to count as making an attempt), the loophole closes. Suppose that generation of $\mathrm{X}$ is not required for a behaviour to count as an attempt, but is required for an attempt to count as a success. Then, given the structure of a guidance-by-need

${ }^{13}$ Compare Bratman 1987, pp. 4, 15-18; Velleman 2000, pp. 202-204.

${ }^{14}$ Compare Frankfurt 1978. 
system, $\mathrm{X}$ is part of what the system is checking for and modulating towards, which is to say, generating $\mathrm{X}$ is part of the goal.

And that is one argument for the lemma. Accidental aboutness cases are failed attempts at ordinary belief-formation. So the aboutness of the resulting beliefs is not required for an attempt at ordinary belief-formation, and is required for a successful attempt. But the motivational state that guides ordinary belief-forming activity is a need. And where an activity is guided by a need, a result which is not required for the subject to count as attempting the activity, but is required for the attempt to count as successful, is part of the activity's goal. So part of the goal of ordinary belief-formation is the aboutness of the resulting beliefs.

\section{The Argument from Fiction}

The second argument for the lemma takes off from consideration of our understanding of fiction. There are, of course, many kinds of fiction - "realistic" novels and stories; non-realistic ones (involving ghosts and magic...); "genre" fictions; films; plays; maybe video games, if we allow that playing the game involves trying to shape a fictional train of events. But the argument of this section deals only with what I shall call "standard" fictions - texts presenting some fictional but realistic train of events, and simulating the descriptions of such trains of events that we standardly create and encounter in non-fictional cases. Consider the question "Could it turn out, without violence to our general conception of the kinds of things in the world and the ways they behave, that we are wrong about the provenance of the text and it is actually a description of fact?" This question provides a rule of thumb for membership in the class of standard fictions: the more obvious a "yes" answer to this question, the more uncontroversial the status of a fictional text as standard. It will not matter that the class of fictions which are "standard" in this sense has fuzzy boundaries: the argument to follow depends only on what holds for central - uncontroversial- cases.

It is a commonplace observation that reading or listening to a fictional text on appropriate terms (reading it as fiction) involves pretence: when you read a text as fiction, you pretend to treat it as describing reality. ${ }^{15}$ The argument begins with a claim about the kind of pretence involved in competent engagement with a standard

${ }^{15}$ Walton 1993, Evans 1982, Lewis 1978 and (especially) 1983, p. 276, Camp 2009, 2017 and many others. 
fiction: engagement with a standard fiction involves what I shall call "genuine pretence", rather than mere "making as if".

To see this distinction, contrast the proceedings of a "mock trial" as run in many law schools, and those of a "show trial" whose purpose is to generate the mere appearance of due process. Participants in a mock trial are engaged in genuine pretence - running the same legal procedures as run in real cases, but within the scope of the understanding that the "facts" of the case may have been fabricated and the court's decision will not have the usual real-world impact. Participants in a show trial are engaged in making as if - running procedures which have been selected for their surface similarity to due process, but whose similarity to genuine (fair, and in place because fair) proceedings is exhausted by the appearance. ${ }^{16}$

Here are some definitions to make this distinction precise:

When a subject "genuinely pretends" to A, the subject's actions are generated by the guidance mechanism that generates the subject's real-world A-ings, running within the scope of pretence.

When a subject "makes as if" to A, the subject's actions are generated by a motivational state directed at producing a behaviour that resembles A-behaviour in relevant respects.

Now recall Case 2 "Aneurin Bevan", and compare it with Case 5:

Case 5 "About thirty years ago, Miss Maria Ward, of Huntingdon, with only seven thousand pounds, had the good luck to capture Sir Thomas Bertram, of Mansfield Park..." This is the opening of Jane Austen's Mansfield Park. You read the opening pages, and form representations you would express using the proper names the text contains.

Case 2 is a case of ordinary belief-formation by uptake from testimony. The current claim is that Case 5 is a genuine pretence case of this same activity. When you read the text in Case 5, and form representations whose contents you would express using the proper names it contains, you arrive at these representations by running the guidance system that operates in Case 2, but doing so within the scope of pretence.

${ }^{16}$ Though approached from a different direction, I take this distinction to be parallel to Camp's distinction between the kinds of pretence involved in what she calls "fictional imagining" on the one hand, and understanding of metaphor on the other. Camp 2009, pp. 111-112. 
What exactly does running this guidance system "within the scope of pretence" involve? One factor will be isolation of the output representation from real-world consequences - from the subject's account of what the real world is like - and from her planning for action. Another factor, this time on the input side, will be variable degrees of isolation from what the subject treats as real-world information. Real uptake from testimony does not usually just generate a body of beliefs from a string of utterances. It combines the utterances with real-world information to produce a much richer account of whatever is being described than could be got from the utterances alone. The uptake from testimony involved in reading a standard fiction will also use some real-world information, but with restrictions which do not apply in the ordinary case. For example, in real world uptake from testimony, if your interlocuter asserts that $\mathrm{p}$ when you know that not-p, the real world information will prevail at the expense of your view of your informant as reliable. In engagement with a standard fiction, this is reversed: $p$ enters as a part of the account of the (fictional) train of events; the fact that in the real world not-p is left behind.

However, my purposes here do not require an official version of what it is for a guidance mechanism to run "in the scope of a pretence". The rough-and-ready account towards which I have already gestured will do: in engagement with fiction, the guidance mechanism of uptake from testimony runs on the string of utterances contained in the fictional text, with characteristic (but as yet unspecified) restrictions on the extent to which real-world information contributes at input, and isolation of the output representation from the subject's account of what the real world is like.

Why should this claim be accepted? I shall take it for granted that engagement with standard fiction involves some kind of pretendtreating-as-testimony. You read the text, and engage in what I shall call "narrative construction" - drawing consequences and filling in gaps in something like the way you do in real-world cases like Case 2. But why think that what is going on is genuine pretence of uptake from testimony, rather than the looser kind of pretence that I have called "making as if"?

One point in favour of the claim is that engagement with standard fictions is a relatively unsophisticated competence which we seem to acquire alongside competence in uptake from testimony itself. This is what we should expect if engagement with standard fiction runs (within the scope of pretence) the same guidance system as runs in ordinary uptake from testimony. In contrast, if what was involved was 
"making as if" pretence, engagement with a standard fiction would require doing something comparatively devious: running a mechanism guided by the intention to treat the text in a way resembling uptake from testimony in relevant respects. ${ }^{17}$

A second point is that there are various aspects of engagement with fiction which seem to cry out for explanation in terms of the "genuine pretence" claim. One such aspect is the phenomenon of "imaginative resistance". ${ }^{18}$ In Mansfield Park, the character Fanny Price is obviously intended by Jane Austen to be a model of good sense. But Fanny is so prone to excited dread, anxious happiness, and headaches brought on by these emotions, that it is difficult for a contemporary reader to see her in this light. This is to be expected if reading the fiction involves running (within the scope of pretence) the actual mechanisms of ordinary belief formation. Suppose your response to a stream of real-world "NN" testimony would be to form a body of beliefs including "NN is a prude" and "NN should stop sweating the small stuff". Then genuine pretence of ordinary uptake from a parallel stream of testimony occurring in a fictional text (with "NN" replaced by "Fanny Price") — will generate pressure towards the parallel outcomes. In contrast, it is hard to see how the phenomenon of imaginative resistance is to be explained if reading fiction is mere making as if.

Finally, consider the possibility of finding out that what you had thought was a fictional character is in fact a real person: you read title $\mathrm{T}$ written by famous novelist $\mathrm{X}$ and compile an "NN" representation, taking it that $\mathrm{NN}$ is a fictional character. You then find out that $\mathrm{T}$ is in fact X's one venture into factual narrative: $\mathrm{NN}$ is a real person. Suppose you also find out that $\mathrm{T}$ is an extremely reliable narrative. There is no reason to doubt the truth of any token sentence it contains. And now consider this question: is it rational for you to upgrade your "NN" representation into a body of beliefs as to what $\mathrm{NN}$ was like? Remember that the "NN" representation does not just replicate the contents of the sentences in the text: it is formed by taking these sentences, drawing consequences, filling gaps, and so on. So our question is not just whether it is rational for you to accept

${ }^{17}$ Obviously a full defence of this point would require engagement with empirical findings on the relative sophistication of the various kinds of pretence. Note that the claim required here is not that making-as-if-to-A is always more sophisticated than genuine pretence of A-ing, but that this is the case when $\mathrm{A}$ is engaged in uptake from testimony.

${ }^{18}$ I take what I say in this paragraph to be in line with the central aspects of the discussions of this phenomenon in Gendler 2000 and Camp 2017. 
the initial sentences as true (we are already supposing that it is). Rather, the question is whether it is rational to move to accepting as mostly accurate the "NN" representation you formed by the "draw consequences; fill in gaps" moves you made while reading the text as fiction. Surely it is. It would be a waste of your time to go back to the text and read it again - engaging with it as fact rather than fiction - because the results would be $(\text { mostly })^{19}$ the same. And how could this be if it were not that engagement with standard fiction consists in running - within the scope of pretence - the same information-marshalling mechanism as is at work in ordinary uptake from testimony ${ }^{20}$

So I shall take it that engagement with standard fiction is a genuine pretence of uptake from testimony. With this claim in place, we can argue for the lemma like this (I shall state the argument in outline, then work through the details):

1 Engagement with standard fiction is genuine pretence of uptake from testimony. (It is as if you say to yourself "I'm pretending but...", then treat the author's words as testimony on the basis of which you construct a narrative in much the same way as you would in response to a real-world testimony stream.)

2 This narrative-constructing activity involves internal commitment to the reality of what is described: in building the narrative the way you do, you are, within the scope of the pretence, treating it as a narrative that describes real events, characters, places, and so on.

3 The narrative-constructing activity also involves recognising that at many points there is no fact of the matter as to what the world of the fiction is like.

There is a tension between $\mathbf{2}$ and $\mathbf{3}$ whose resolution demands that we accept 4:

4 The internal commitment to reality involved in engagement with standard fiction is commitment, within the scope of pretence, to using

\footnotetext{
${ }^{19}$ There might be differences generated by the differences in how we incorporate real-world information when we are reading-as-fact vs. reading-as-fiction, but these differences are minimised by the supposition that the text is reliable (so that instances where the text contains $\mathrm{p}$ but the reader knows that not $\mathrm{p}$ are few and far between).

${ }^{20}$ Compare Evans on the "game to reality shift": Evans 1982, p. 362.
} 
the text to secure and sustain aboutness relations with individuals (individual people, places, things, and events).

This is a conclusion about engagement with standard fiction. But given 1, it upgrades into a conclusion about the real-world case. Recall the definition of "genuine pretence" from a few pages ago:

When a subject "genuinely pretends" to A, the subject's actions are generated by the guidance mechanism that generates the subject's real-world A-ings, running within the scope of pretence.

Given 1, this definition, if genuine pretence at an activity involves acting under a commitment within the scope of pretence, real-world engagement in the activity involves acting under the commitment for real. So $\mathbf{1}$ and $\mathbf{4}$ entail $\mathbf{5}$ :

5 Part of the aim of ordinary uptake from testimony is to secure and sustain aboutness relations with individuals.

And $\mathbf{5}$ is the lemma for the case of ordinary uptake from testimony.

A full version of the argument requires further discussion of $\mathbf{2}$ and $\mathbf{3}$; an account of why there is tension between them; and an account of how the need to resolve this tension forces the move to 4 .

Let us start with $2 .{ }^{21}$ Following many others, I have taken it that the narrative construction characteristic of engagement with a standard fiction involves some kind of pretence of reality. Now consider two accounts of how the pretending-real relates to the narrative construction: 2 from the argument, and the alternative:

2 from the argument - The narrative construction in itself involves internal existential commitment. Just building the narrative the way you do is already pretending the events and characters are real.

The alternative - The narrative construction does not in itself involve internal existential commitment. It involves only building up a coherent picture; to add existential commitment you have to add affirmation (you add a "pretend it's real" rider from outside the narrative-constructing activity).

Suppose the alternative. Then it is not enough, for it to count as treating Fanny Price as a real character in Mansfield Park, just that you take the relevant parts of Jane Austen's text and form a "Fanny

${ }^{21}$ The argument for 2 that I present adapts an argument from Martin 2002. Soteriou 2016, pp. 66-74 provides a useful discussion of Martin's central moves. 
Price" representation by drawing consequences and filling in gaps in the usual "competent engagement with standard fiction" way. Rather, you must do all that - form your "Fanny Price" representationand add "and pretend she's real" as an additional undertaking. But this just cannot be right. The fact that you are pretending that Fanny is real is already there as the answer to the question "Why does your 'Fanny Price' representation evolve the way it does?" Your representation is formed by taking relevant sentences from the text, drawing consequences, and filling in details. But in selecting some sentences and not others as carrying inputs to your "Fanny Price" representation, you are already, within the scope of pretence, treating "Fanny Price" as an ordinary proper name. And in drawing consequences and filling in details as you do, you are, within the scope of pretence, taking it that Fanny is a real person: that is why you take it, within the scope of the pretence, that Fanny interacts causally with various objects and people and that her trajectory evolves (within the pretence) in an "is a real person" way. Your "Fanny Price" representation is not just built up using coherence constraints or aesthetic constraints. Responding to the text as you do is already pretending that Fanny is real; there is no work for an extra "and I'll pretend she's real" rider to do.

This gives us $\mathbf{2}$ in the argument. What about $\mathbf{3}$ ?

Again, I shall take it that engagement with standard fiction involves some kind of recognition that there is simply no fact of the matter on many points of detail. To bring out the force of $\mathbf{3}$ in the argument, we must be clear about what the relevant "recognition that there is no fact of the matter" involves. It is not that both $p$ and not-p are "left open" in that we do not know which of them is the case, but take it that one of them is. Nor is it just that narrative-constructingactivity runs its course, and the "world" of the fiction is determinate only up to the level of the description that is generated (so that there might be said to be multiple "worlds" of the fiction ${ }^{22}$ - sharing the details which are fixed by narrative construction; differing over those on which the resulting narrative is silent). Neither of these kinds of "leaving it open" would be in tension with 2 . In either case, the claim might just be that the activity of narrative construction involves both commitment to the reality of what is described, and recognition that the activity is going to come to an end before it generates a complete description.

${ }^{22}$ Compare Lewis 1978, p. 42: "The worlds of Holmes are plural." 
The tension between $\mathbf{2}$ and $\mathbf{3}$ arises because recognition that there is no fact of the matter is, in ways that I am about to explain, built into the activity of narrative construction itself. There are moves we make in the course of engagement with standard fiction, as part of the activity, which are constitutive of standard-fiction-type "leaving it open". Given 2, narrative construction proceeds as it does partly because the reader is treating the events as real: it is because you are treating what is described as real that you respond to the text as you do. Given 3, your response is also shaped by your recognition that there are no facts of the matter on many points of detail. So here is the problem: to explain how it can be that a narrative-constructing activity proceeds as it does because the subject is treating what is described as real, when many steps in the activity unfold as they do because the subject recognises that details which would be fixed if what was described was real are to be treated as "no fact of the matter" within the activity.

4 states the solution I propose. The "internal commitment to reality" involved in reading a fictional text consists in treating the text as sustaining a perspective upon individuals (that is, individual things, places, people, and events).

To bring out how this suggestion resolves the tension between 2 and 3, I shall work through one kind of move which I take to be constitutive of standard-fiction type "leaving it open," and show how 4 eliminates the tension between making this kind of move and treating what the fiction describes as real. (I discuss a second kind of "leaving it open" move in section 5.)

The "leaving it open" move that I shall consider concerns what I shall call "limits on creativity" in engagement with standard fictions. The narrative construction involved in reading a standard fiction involves drawing consequences and filling in gaps. But how much drawing of consequences and filling in of gaps is in order? In the philosophical discussion of fiction, this question is most familiar from attempts to explain the extent to which narrative construction should draw upon what the reader (or the author's intended readership...) regards as real-world information. But the question also arises for the drawing of consequences from what is explicitly specified in the text. Suppose that painstaking tallying of details and ingenious inference would enable you to draw the conclusion that the chair upon which Lady Bertram is sitting in some scene in Mansfield Park has striped upholstery. (Suppose that it is specified at some point that all the chairs in the drawing room are either striped or checked, but Jane 
Austen is evidently not herself keeping track of the details that enable the "striped" conclusion, and there is nothing about her description of the scene which makes the upholstery an important issue). Is it a (pretend) fact in the "world" of Mansfield Park that in this scene Lady Bertram is sitting in a striped chair (so that, for example, a film adaptation in which she is sitting in a checked one thereby counts as not true to the text)? I take it that the answer to this question is "no". Mining the text to extract conclusions at this level of fineness of grain is not a way to uncover hidden pretend-facts: it is a way to end up with a pretence which treats as fixed details which actually have "no fact of the matter" status. Engagement with standard fiction involves holding back from what I shall call "overly creative" drawing of conclusions and filling in of gaps - pursuing these elements of narrative construction to the point where they fix details which should be left open.

Now compare this with belief formation outside the scope of pretence. When it comes to your account of what the real world is like, the analogue of what I have called "overly creative" inference in the fictional case might lead you to find out things that are not relevant to your practical purposes. But, as long as your inferences are sound, it cannot lead you wrong with respect to your account of what the world is like considered independently of these purposes: you will end up uncovering facts, just unimportant ones.

So we have a more specific instance of the tension between $\mathbf{2}$ and $\mathbf{3}$ in the argument. The narrative-constructing activity characteristic of engagement with standard fictions involves internal commitment to the reality of what is described. But engagement in the activity also involves holding back from investigations of a kind which, in a real case, would fill in real details. In real world cases, we often hold back from investigation where the details it would uncover would be irrelevant to practical purposes. But when we engage with standard fictions, the reason for holding back is different: it is not that being "too creative" would take you to irrelevant pretend-facts: it is that it would be treating as fixed details which have "no fact of the matter" status.

4 in the argument proposes a resolution to this tension. The internal commitment to reality in engagement with standard fiction consists in the pretence of using the text to sustain a testimonybased perspective on individuals. When you read Mansfield Park, you engage in pretences of treating the "Fanny Price" and "Sir Thomas Bertram" strands in the text as inputs to testimony-based 
representations of people. Engagement in these pretences involves deployment, within the scope of the pretence, of the ordinary mechanisms of uptake from testimony, using the parts of the text that these mechanisms treat as relevant to sustain a representation which has the structure of the bodies of beliefs we form by uptake from streams of "NN" testimony in real life. Overly creative reading - trying to "work out" details which are not there at output when the input has been processed to the level involved in the pretence of aboutnesspushes processing beyond the aim of the activity.

To consolidate the move here, suppose we try to run the same line of thought, replacing "the pretence of using the text to sustain aboutness relations with individuals" with "the pretence of using the text to sustain a perspective on a world". In this case, the claim will be that the details fixed by engagement with the fiction are those there at output when the input has been processed up to the level required to engage in pretence of sustaining a perspective on the world. But what level is that? The instruction "take this stream of text and use it to pretend to sustain a perspective on a person" carries with it an imprecise indication of where to stop: use all the text that is provided; draw consequences and fill in gaps to give the representation the unity and trajectory characteristic of the bodies of belief we arrive at by real-life uptake from streams of "NN" testimony. The goal "use this input to pretend to sustain a perspective on a world" carries no such approximate indication of how much working out of details you should (within the scope of pretence) do. So the suggestion that engagement with standard fiction is pretence of sustaining a perspective on a world cannot explain how this activity can both carry internal commitment to reality, and involve recognition that there are levels of investigation which are inappropriate because they fix details which have "no fact of the matter" status. ${ }^{23}$

${ }^{23}$ It may be tempting to suggest that the aim of the narrative construction is to deliver a perspective on a world up to a given resolution. In intuitive terms, the suggestion would be that belief-forming activity in both real and "engagement with fiction" cases is like construction of a map of the distribution of properties in the world, with the degree of resolution of the map coming from the "question under discussion" in the context. (Compare Lewis 1988; Yalcin 2018.) But note that the suggestion cannot be that there is an approximately uniform resolution at which we are aiming across the whole narrative: it is a familiar aspect of standard fictions that levels of detail vary widely between different characters, events, places, and so on; and for the same characters in different scenes. Appeal to "questions under discussion" regarded as somehow specified in the text could get us only as far as, within the scope of the pretence, treating unfixed details as irrelevant to the question 
So we have a second argument for the lemma. There is a tension between two central aspects of the narrative construction involved in engagement with standard fiction. On the one hand, this narrative construction proceeds as it does because the reader is, within the scope of pretence, treating what is described as real. On the other, it proceeds as it does because the reader is treating as unfixed details which would be fixed in a real case. The gloss I have proposed on the "treating as real" involved in engagement with standard fiction eliminates this tension: this "treating as real" consists in, within the scope of pretence, using the text to sustain testimony-based aboutnessrelations with individuals. But engagement with standard fiction is genuine pretence. So this conclusion about what we are trying to do, within the scope of pretence, when we engage with standard fiction upgrades into a conclusion about what we are trying to do for real in the ordinary case: part of the aim of ordinary uptake from testimony is to secure and maintain aboutness relations with individuals.

\section{An Application - Aboutness Is Cognitive Focus ${ }^{24}$}

I have called the claim defended in the last two sections a "lemma" because of the role I think it plays in generating a range of conclusions about our cognitive engagement with the world. We already have some negative conclusions: if the lemma is true, each of the lemma-denying views on pp. 15-17 is false. But the lemma's importance will emerge fully only upon exploration of its positive consequences. This section sketches one such consequence: the lemma generates new foundations for the theory of reference.

Recall Cases 1 and 2 from the start of the paper:

Case 1 You are in an ordinary situation in which you have no reason to doubt the deliverances of perception. Looking at an orange on the table in front of you, you form, by uptake from perception, a body of beliefs you would express using sentences containing "that".

Case 2 You have not heard the name "Aneurin Bevan" before. Somebody begins to explain who Bevan was...: You take the utterances

at issue, rather than as having "no fact of the matter" status. It remains open to say that the aim of narrative construction is to construct a perspective on a world, with degrees of resolution localised to individuals. But that brings us back to the proposal in the main text.

${ }^{24}$ This section presents an improved and streamlined version of the main argument of ch. 2 of Dickie 2015. I take the main advance to be recognition of the role played by the lemma. 
at face value, forming a body of beliefs you would use the name "Aneurin Bevan" to express.

In each of these cases, I take it that there is a clear (intuitive...) answer to the question "Which object are your beliefs about?" In Case 1 they are about the orange. In Case 2 they are about the politician Aneurin Bevan. I also take it that there are uncontroversial initial answers to this question: "Why is this the thing your beliefs are about?" In Case 1, your beliefs are about the orange because it is at the end of your perceptual-attentional channel. In Case 2 they are about Aneurin Bevan because they are formed by uptake from a stream of testimony composed of utterances themselves about him - the aboutness of your beliefs is inherited from aboutness in the testimony stream on which they are based. But to allow that these relations do secure aboutness is to say nothing about how they do their aboutness-fixing work: how perceptual attention to objects enables thought about them; how aboutness is transmitted from speaker to hearer in ordinary cases of uptake from testimony.

This "how?" question was the focus of the traditional theory of reference - the question to which "descriptivist" and "causalist" views of reference-fixing were answers. Descriptivists said that the aboutness-fixing relations do their work by generating a description that the object satisfies and to which the subject is appropriately related. Causalists attempted to find a causal relation present in all and only cases of aboutness. The lemma generates a new approach to this traditional question.

The new approach is most easily introduced using a toy example. Consider an astronomer (hereafter " $A$ ") compiling a report from the data delivered by a telescope focussed on object $o$ in the night sky. $A$ has no reason to doubt that the telescope is working as it should. The telescope delivers a stream of data: detection of motion; detection of fluctuating temperature; and so on. $A$ compiles her report: "It's moving. Its temperature is fluctuating between suchand-such values...." The fact that the telescope is focussed on $o$ obviously does not guarantee that $A$ 's report will match what $o$ is like. Some unlucky spoiler might intervene: a concealed fault in the workings of the telescope; a rare data-distorting anomaly in $o$ 's part of the sky. But the fact that the telescope is focussed on $o$ does guarantee the following: $A$ 's report will match what $o$ is like unless some unlucky spoiler intervenes.

The new approach to the theory of reference that I am about to sketch treats the aboutness of our ordinary thoughts as a kind 
of focus - what I shall call "cognitive focus". Consider the "how" question for Case 1: How does an attentional perceptual link with an object put you in a position to think about it? According to the new framework I am going to propose, the perceptual link does its aboutness-fixing work by making available a means of justification - uptake from the perceptual channel — which will deliver beliefs which match what the attended object is like unless some unlucky spoiler intervenes. And, according to the new framework, something similar holds for Case 2: A testimony-link of the kind illustrated by this case enables thought about the object at the end of the chain by making available a means of justification - uptake from the perceptual channel- such that the subject will be unlucky if beliefs justified in this way do not match what the object is like, and not merely lucky if they do.

A full defence of the new framework would extend the paper to an antisocial length. In what follows I shall provide an abridged defence, directed towards clarifying the framework's central principle, and bringing out how the lemma contributes to establishing it.

The central principle is what I shall call "ABOUTNESS AND JUSTIFICATION". It sits near two other principles which will play a role in establishing it:

ABOUTNESS AND TRUTH - If a belief is about an object, its truth or falsity depends on what the object is like. (If my belief that Jack has fleas is about my dog, it is true iff he has fleas.)

TRUTH AND JUSTIFICATION - Justification is truth conducive: the factors that secure justification for a belief do not guarantee that the belief is true, but they do guarantee that is true across rationally relevant circumstances (where the "rationally relevant" circumstances just are those across which justification guarantees truth; if justification for a belief leaves it a matter of chance whether the belief is true, the circumstance is thereby rationally irrelevant). ${ }^{25}$

Against the background of these two principles, the first connecting aboutness and truth, the second truth and justification, we should expect to find a third principle which cuts the intermediate term, thereby connecting aboutness and justification. And we are going

${ }^{25}$ Alternative ways of making the claim that justification is truth-conducive precise would generate differences in the line of thought that follows, but not in ways that will matter here. 
to find such a principle - but only using the lemma established in earlier parts of this paper. Here it is:

ABOUTNESS AND JUSTIFICATION - A subject's body of $\langle\alpha\rangle$ beliefs is about object $o$ iff their associated pattern of justification is conducive to getting $o$ 's properties right (so that, across rationally relevant circumstances where the subject forms $\langle\alpha$ is $\Phi>$ beliefs justified by this pattern, $o$ is $\Phi$, and the match between the beliefs and $o$ is secured by the subject's justification).

(A full-dress defence of the framework would go into details here concerning the notion of a "pattern of justification" associated with a body of beliefs, but I shall slide over these details here. For the cases I have used to illustrate the notion of ordinary belief-forming activity, this notion is relatively straightforward: in Case 1, beliefs are justified by uptake from an attentional perceptual channel; in Case 2 they are justified by uptake from the stream of "Aneurin Bevan" testimony. Complications arise when it comes to generalising the framework beyond this kind of "pure" (single pathway to justification) case. I shall ignore these complications here for the sake of brevity. This note $^{26}$ gives an indication of the issues arising.)

ABOUTNESS AND JUSTIFICATION is a biconditional linking aboutness on the left hand side, and what I have called "cognitive focus" on the right. To establish the biconditional, we shall argue for each direction in turn.

Here is an argument for the left-to-right direction - if aboutness then cognitive focus. This part of the argument does not need the lemma:

Suppose

1 S's belief that $<\alpha$ is $\Phi>$ is about $o$.

\section{Add ABOUTnESS AND TRUTH:}

\footnotetext{
${ }^{26}$ Note first that there is no suggestion that the notion of justification is to be explained in terms of that of a pattern of belief formation taken as prior, so familiar worries from the literature on "reductive reliabilism" (compare Conee and Feldman 1998) do not bite. However, the notion of a "pattern of justification" still needs an explanation. My current preferred option is to explain it away, leaving a reformulation of the principle that looks something like this: Consider subject $\mathrm{S}$ engaged in maintaining a body of $\langle\alpha\rangle$-beliefs. These beliefs are about object $o$ iff, for all $\langle\Phi\rangle$, across the $\sigma$ where $\mathrm{S}$ forms $\langle\alpha$ is $\Phi>$ beliefs by rationality-securing pathways involving the smallest deviations from or extensions to S's actual beliefforming activity, either $o$ is $\Phi$ and the match between S's belief and $o$ is secured by S's pathway to the belief, or $\sigma$ is rationally irrelevant.
} 
2 If S's belief that $\langle\alpha$ is $\Phi>$ is about an object, the belief is true iff that object is $\Phi$.

$\mathbf{1}$ and $\mathbf{2}$ entail

3 S's belief that $\langle\alpha$ is $\Phi>$ is true iff $o$ is $\Phi$.

\section{Add TRUTH AND JUSTIFICATION:}

4 Justification for a belief eliminates every rationally relevant circumstance where the belief is not true (it guarantees the belief's truth across rationally relevant circumstances).

\section{$\mathbf{3}$ and $\mathbf{4}$ entail}

5 Justification for the belief that $<\alpha$ is $\Phi>$ eliminates every rationally relevant circumstance where $o$ is not $\Phi$.

So we have the left-to-right direction of the ABOUTNESS AND JUSTIFICATION biconditional:

6 If $\mathrm{S}^{\prime} \mathrm{s}<\alpha$ is $\Phi>$ belief is about $o$, justification for the belief eliminates every rationally relevant circumstance where $o$ is not $\Phi$.

The argument for the right-to-left direction (if cognitive focus then aboutness) does need the lemma. It also needs one additional piece of apparatus. The additional apparatus makes explicit the connection between competence at an activity and non-lucky success. I shall say that a behaviour is an "exercise" of competence at fulfilling a motivational state iff it is guided by the state, and is a non-lucky generator of this state's fulfilment. I shall gloss the notion of "non-luckiness" in terms of success-conduciveness across relevant circumstances: the "relevant" circumstances are those across which a behaviour guided by a motivational state must guarantee success if it is to count as an exercise of competence at fulfilling the state. An exercise of competence might fail to deliver success, but only if some unlucky spoiler intervenes, in which case the circumstance is irrelevant. Finally, I shall say that a behaviour "manifests" the competence iff it is an exercise of the competence in relevant circumstances (in which case the result will be success secured by the subject's exercise of the competence). (Again, think about Andy playing a shot at tennis. He is "exercising" his competence iff everything goes well with respect to his information processing, so that he will be unlucky if the ball does not go where he intends to put it. He is "manifesting" his competence iff he is exercising it and his circumstance is not unlucky: 
the ball goes where he wants it to because the circumstance is one in which exercise of competence guarantees success. $)^{27}$

For the case of ordinary belief formation, I shall take it that the notion of exercise of competence is coordinated with the notion of justification: an instance of ordinary belief-forming activity is an exercise of ordinary belief-forming competence iff the resulting beliefs are justified. And I shall take it that the notion of "rational relevance" as it occurs in TRUTH AND JUSTIFICATION just is the notion of relevance from the point of view of ordinary belief formation: the rationally relevant circumstances are those where exercise of beliefforming competence also manifests this competence. (So TRUTH AND JUSTIFICATION says that manifestation of belief-forming competence guarantees the truth of the resulting beliefs.) ${ }^{28}$

Now consider a subject maintaining a body of ordinary beliefs in such a way that the cognitive focus condition is met with respect to object $o$ (suppose the beliefs are justified, and their means of justification guarantees a match with $o$ across rationally relevant circumstances). Could these beliefs fail to be about $o$ ? We shall suppose "yes", and use materials now in place to derive a contradiction:

\section{Suppose}

1 It is not sufficient, for S's $\langle\alpha\rangle$ beliefs to be about $o$, that the cognitive focus condition be met with respect to $o$.

Given 1, the following combination is coherent. $\mathrm{S}$ has a body of justified $<\alpha$ is $\Phi>$ beliefs. There is no spoiler interfering with any "detection of $\Phi$-instantiation" aspect of S's path to these beliefs. There is a unique object, o, upon whose $\Phi$-ness, or not, S's $\Phi$ detecting procedures are picking up. (More precisely, $o$ is the object such that, for all $\langle\Phi\rangle$, S's justification for believing $\langle\alpha$ is $\Phi>$ eliminates $o$ 's non- $\Phi$-ness across relevant circumstances.) But $\mathrm{S}$ 's $<\alpha>$-beliefs are not about $o$.

2 In the scenario just described, S's circumstance is either rationally relevant to S's belief-forming activity or it is not (where the "rationally relevant" circumstances are those across which exercise of

\footnotetext{
${ }^{27}$ I adopt the terms "exercise" of a competence and "manifestation" of a competence from Sosa 2015.

${ }^{28}$ Again, this is consistent with Sosa's "virtue reliabilist" epistemology, but I make no claim that the traditional epistemological notion (justification) is to be explained in terms of the practical notion (exercise of a competence) taken as prior.
} 
belief-forming competence also manifests this competence, which is to say, guarantees success at the aim of belief-forming activity).

Given the lemma, we have an argument for 3:

3 The circumstance is not rationally relevant to S's belief-forming activity (it is not a circumstance where exercise of competence guarantees success).

For on the face of things $\mathrm{S}$ is deploying belief-forming competence in her formation of $\langle\alpha$ is $\Phi>$ beliefs. We are supposing that she is forming a body of $<\alpha$ is $\Phi>$ beliefs which she treats as about a single object, on the basis of positive tests for $\Phi$-ness which are indeed picking up on the $\Phi$-ness or not of some one particular thing. (If the reader thinks competence at ordinary belief-formation involves some factor in addition to this, the author demands that it be produced.) But we are also supposing that S's $\langle\alpha\rangle$-beliefs are not about $o$, and that $o$ is the unique object for which the cognitive focus condition is met with respect to these beliefs. Given the argument for the left-toright direction of the biconditional, already in place, it follows that the beliefs are about nothing. So if the circumstance is rationally relevant, it is a rationally relevant circumstance in which ordinary belief-forming competence generates beliefs about nothing. But given the lemma, part of the aim of ordinary belief formation is to secure and maintain aboutness relations. So if the circumstance is rationally relevant, it is a rationally relevant circumstance in which competence in the activity of ordinary belief formation is exercised, but the aim of this activity is not fulfilled. Contradiction.

And we also have an argument for $\mathbf{4}$ :

4 The circumstance is not rationally irrelevant to S's formation of the belief.

To see the argument for $\mathbf{4}$, note first that the circumstance is not rationally irrelevant to S's formation of the corresponding beliefs that $<$ Something is $\Phi>$. For in the circumstance as described, there is nothing devious interfering with S's detection of $\Phi$-instantiation: in forming a $<$ Something is $\Phi>$ belief on the basis of the means of $\Phi$-detection that underpins justification for her $\langle\alpha$ is $\Phi>$ beliefs, $\mathrm{S}$ would be manifesting belief-forming competence, and a circumstance in which formation of a belief by rationality-securing means manifests 
belief-forming competence just is a circumstance rationally relevant to the belief's formation.

Given that the circumstance is rationally relevant to S's formation of $<$ Something is $\Phi>$ beliefs, to deny $\mathbf{4}$ is to endorse the possibility of the following combination:

A circumstance rationally irrelevant to formation of the belief that $<\alpha$ is $\Phi>$ may be rationally relevant to formation of the belief that $<$ Something is $\Phi>$.

And to endorse this possibility is to suppose that the conditions for the rationality of a $<$ Something is $\Phi>$ belief might be more demanding than those for the rationality of the corresponding ordinary $<\alpha$ is $\Phi>$ belief. For example, it is to suppose that it might be rational to believe $<$ That is square $>$ by uptake from a perceptual link, but irrational to believe $<$ Something is square $>$ on the same justification (because the rationality of the $<$ Something is square $>$ belief requires the elimination of extra "nothing square there" circumstances - circumstances that must be guarded against if it is to be rational to move to $<$ Something is $\Phi>$ on the basis of perception, but may be ignored in moving to $<$ That is $\Phi>$ ). And this just gets things the wrong way around. In ordinary belief formation -illustrated by Cases 1 and 2 from the start of the paper- justification for believing $<\alpha$ is $\Phi>$ automatically generates justification for believing $<$ Something is $\Phi>$ too.

Having established $\mathbf{3}$ and $\mathbf{4}$, we have eliminated both disjuncts of $\mathbf{2}$. But the choice at $\mathbf{2}$ is generated by a situation whose coherence is entailed by $\mathbf{1}$, so $\mathbf{1}$ must be rejected, giving us $\mathbf{5}$ :

5 If the pattern of justification associated with a body of beliefs is such that, for all $\langle\Phi\rangle$, justification for believing $\langle\alpha$ is $\Phi>$ guarantees that $o$ is $\Phi$ across rationally relevant circumstances, these beliefs are about $o$.

So we have both directions of the ABOUTNESS AND JUSTIFICATION biconditional: if there is aboutness, there is cognitive focus; if there is cognitive focus, there is aboutness.

The argument for ABOUTNESS AND JUSTIFICATION is only a first step towards an account of how the relations that enable us to think about ordinary things do their aboutness-fixing work. ${ }^{29}$ But it is

${ }^{29}$ Dickie 2015 applies the new approach to a range of questions about aboutness and reference. 
perhaps already possible to see how this principle - established from the lemma- opens up a new approach to this traditional problem. Given ABOUTNESS AND JUSTIFICATION, explaining aboutness-fixing for perceptual demonstrative thoughts will be a matter of explaining how an attentional perceptual link with an object generates a relation of cognitive focus with the object - making available a means of justification such that beliefs justified in this way will match what the object is like unless some unlucky spoiler intervenes. Explaining transmission of aboutness from the speaker who uses a proper name to the hearer who takes up its use will involve something similar: explaining how the transaction transmits cognitive focus, so that if the speaker is using "NN" as a name for $o$, uptake from the speaker's "NN" testimony provides the hearer with a means of justification which tends to get $o$ 's properties right.

Though there is obviously much more to be said, I hope I have done enough to bolster the immodest claim from the beginning of this section: the lemma generates new foundations for the theory of reference.

\section{Engagement with Standard Fictions as Pretence at Sustaining Cognitive Focus}

The aim of the paper so far has been to show how reflection on aboutness failure can inform development of a right account of aboutness-fixing. This reverses a widespread tendency in discussions of aboutness-failure: to treat "And it solves the problem of empty names!" as an additional argument for an account of aboutness or reference whose internal structure is arrived at by looking at "good" cases alone. Nevertheless, if what I have said is along the right lines, we should also expect to find light shining in the traditional direction - the account of aboutness-fixing illuminating the dark workings of empty names. I shall close by bringing out one such point of illumination: the account of aboutness-fixing I have proposed sheds new light on our cognitive dealings with inconsistencies in standard fiction.

Consider the following cases:

(a) From Mansfield Park

"Sitting and calling to Pug, and trying to keep him from the flower beds, was almost too much for me", pp. 69-70. 
"And I will tell you what Fanny [...] the next time Pug has a litter, you shall have a puppy", p. 308.

\section{(b) From Patrick O’Brian’s Aubrey-Maturin novels}

"Whose was that arm?" asked Jack.

"Reade's" said Stephen. "I have just taken it off at the shoulder." The Nutmeg of Consolation, pp. 39-40.

Her one-armed Captain [Reade] was already half-way up the frigate's side, extraordinarily nimble with his hook. The Hundred Days, p. 48.

"I have no doubt that you remember that exceptionally amiable young man with one hand replaced by a steel hook: his name is William Reade [...]" Blue at the Mizzen, p. 188.

\section{(c) From Robinson Crusoe}

I resolved, if possible, to get to the ship; so I pulled off my clothes-for the weather was hot to extremity-and took the water. [He swims out to the wreck.] I found that all the ship's provisions were dry and untouched by the water, and being very well disposed to eat, I went to the bread room and filled my pockets with biscuit and ate it as I went about for other things, pp. 96-97

Suppose you are reading a standard fiction, and come across this kind of inconsistency. What will your narrative-constructing move be? I take it that this question has a strikingly uniform answer. You drop just enough determinacy from the account of the issue at hand to remove the inconsistency. Lady Bertram has a pug called "Pug", its gender not a fact of the matter. Reade has lost quite a lot of his arm - there is no fact of the matter as to exactly how much. Crusoe left all or most of his clothing on the beach, swam out to the wreck, found some dry biscuit, and munched on it as he looked for more supplies. (I stress that this kind of response to inconsistency is characteristic of engagement with standard fiction, not with all fiction. Fictions in which the inconsistency is somehow to be "swallowed" - those for which engagement with the fiction requires that what is described is in fact inconsistent - are not standard (see the rule of thumb on p. 9). ${ }^{30}$ Though arguing for this claim would take us too far afield,

\footnotetext{
${ }^{30}$ So the class of standard fictions does not include those for which Lewis 1983 proposes the "method of union", and Badura and Berto 2019 introduce "impossible worlds".
} 
my own view is that swallowing inconsistencies in engagement with fiction is "making as if" rather than genuine pretence. Obviously, engagement with any particular fiction might involve elements of both.)

Now, here is a question: Why, in response to (a)-(c)-type inconsistencies, do we make this specific kind of move? In each case, we are preventing the inconsistency in the text from infiltrating the constructed narrative. But there are other ways this might be done. For example, with respect to (a) the suggestion might be that the original Pug dies somewhere along the timeline of the story and is replaced by another, or that Lady Bertram has (all along) two pugs, both called "Pug". In (c) it might be that Crusoe swims out to the wreck having removed all his clothes, but takes his jacket with him, perhaps carried above his head on a stick. In responding to (a)-(c), we are not just maintaining consistency, but maintaining it in a very specific way. Why this way rather than some other? (Note that it will not do to say that the move we in fact make captures what all the possible ways of retaining consistency have in common: the possible ways of maintaining consistency are too varied and the kind of move we in fact make too specific for that. Note also that the suggestion that the move captures what every legitimate way of retaining consistency ${ }^{31}$ has in common simply raises the question in another form: What makes these the legitimate ways of retaining consistency?)

And here is the answer that the argument of this paper generates. Engagement with standard fiction is genuine pretence of uptake from testimony. That is, to engage in this activity is, within the scope of pretence, to use the text to secure and sustain aboutness relations with individuals (individual people, places, things, and events). But aboutness is cognitive focus. So the narrative-constructing activity that is engagement with standard fiction is pretence at the activity of maintaining relations of cognitive focus. In our dealings with focusable instruments (telescopes; binoculars), one way to achieve focus, given what registers at first as an incoherent information-feed, is to change resolution: zoom in or out, and what was a blurred or chaotic image resolves itself into focussed contact with a particular thing. The same holds for the maintenance of cognitive focus. An information feed which does not sustain cognitive focus relative to a fine-grained property might do so when the resolution is decreased. In such a case, even if you are not in a position to increase the quality of the information you are getting, you still have a way to

${ }^{31}$ In terms of the framework of Lewis 1978 and 1983, every legitimate "revision". 
achieve focus on the basis of the unimproved information feed: decrease resolution; treat the information feed as justifying ascription of a coarse-grained property rather than a fine-grained one. And this is what we do in the (a)-(c)-cases: Lady Bertram has a pug; Reade loses quite a lot of his arm; Crusoe walks around the wreck eating biscuit, his state of dress or undress unspecified.

Note that in cases of real uptake from testimony, we would treat this kind of inconsistency as indicating the unreliability of the informant. If I tell you that the sheep I am looking at is a Suffolk, and a few minutes later that it (the same sheep) is a Romney, your move will not be to treat me as a reliable source of the information that the sheep belongs to the least general breed-class under which the breeds Suffolk and Romney both fall. It will be to doubt my reliability, either as a source on sheep-breeds in general, or as a source on the matter in this instance. So (going back to the direction of inquiry favoured in most of this paper) this is one of the many respects in which examination of pretence cases reveals or highlights aspects of ordinary belief formation which are hidden if we consider only how this activity unfolds in the real world. ${ }^{32}$

\section{REFERENCES}

Adams, F., 1979, "The Goal-State Theory of Function Attributions", Canadian Journal of Philosophy, vol. 9, no. 3, pp. 493-518.

Anscombe, G.E.M., 1957, Intention, Blackwell, Oxford.

Austen, J., 1814, Mansfield Park, Thomas Egerton, London. Project Gutenberg, release date 2010.

Badura, C. and F. Berto, 2019, "Truth in Fiction, Impossible Worlds, and Belief Revision", Australasian Journal of Philosophy, vol. 97, no. 1, pp. 178-193.

Benacerraf, P. and H. Putnam (comps.), 1983, Philosophy of Mathematics Selected Readings, Cambridge University Press, Cambridge.

Bratman, M., 1987, Intentions, Plans, and Practical Reason, CSLI, Stanford.

Burgess, A. and B. Sherman (comps.), 2014, Metasemantics: New Essays on the Foundations of Meaning, Oxford University Press, Oxford.

Camp, E., 2017, "Perspectives in Imaginative Engagement with Fiction", Philosophical Perspectives, vol. 31, no. 1, pp. 73-102.

32 Thanks to Mike Martin, Dominic Alford-Duguid, an anonymous referee for this journal, and audiences at the Oxford Philosophy of Mind Workshop and the St. Andrews Philosophy Department Reflectorium. 
Camp, E., 2009, “Two Varieties of Literary Imagination: Metaphor, Fiction, and Thought Experiments", Midwest Studies in Philosophy: Poetry and Philosophy, vol. 33, no. 1, pp. 107-130.

Campbell, J., 2002, Reference and Consciousness, Oxford University Press, Oxford.

Conee, E. and R. Feldman., 1998, "The Generality Problem for Reliabilism", Philosophical Studies, vol. 89, no. 1, pp. 1-29.

Cumming, S., 2014, "Discourse Content", in A. Burgess and B. Sherman 2014, pp. 214-230.

Davidson, D., 1980, Essays on Actions and Events, Oxford University Press, Oxford.

— 1980a, “Actions, Reasons, and Causes", in D. Davidson 1980.

—, 1980b, "Intending", in D. Davidson 1980.

Defoe, D., 2015, The Life and Adventures of Robinson Crusoe, Project Gutenberg edition.

Dickie, I., 2015, Fixing Reference, Oxford University Press, Oxford.

Evans, G., 1982, The Varieties of Reference, Oxford University Press, Oxford.

Frankfurt, H., 1978, "The Problem of Action", American Philosophical Quarterly, vol. 15, no. 2, pp. 157-162.

Gendler, T., 2000, "The Puzzle of Imaginative Resistance", Journal of Philosophy, vol. 97 no. 2, pp. 55-81.

Heck, R., 2017, "Cognitive Hunger: Remarks on Imogen Dickie's Fixing Reference", Philosophy and Phenomenological Research, vol. 95, no. 3, pp. 738-744.

Hilbert, D., 1983, "On the Infinite", in P. Benacerraf and H. Putnam 1983.

Horn. L. and G. Ward (comps.), 2004, The Handbook of Pragmatics, Blackwell, Oxford.

Kripke, S., 2013, Reference and Existence, Oxford University Press, Oxford.

Lewis, D., 1988, "Relevant Implication", Theoria, vol. 54, no. 3, pp. 161174.

- 1983, "Postscript to Truth in Fiction", Philosophical Papers: Volume 1, Oxford University Press, New York, pp. 276-280.

- 1978, "Truth in Fiction", American Philosophical Quarterly, vol. 15 , no. 1, pp. 37-46.

Martin, M., 2002, "The Transparency of Experience", Mind and Language, vol. 17 , no. 4, pp. 376-425.

Nagel, E., 1977, "Goal-Directed Processes in Biology", The Journal of Philosophy, vol. 74, no. 5, pp. 261-279.

O'Brian, P., 2008, The Nutmeg of Consolation, Harper Perennial, London. , 2003a, The Hundred Days, Harper Collins, London.

—_, 2003b, Blue at the Mizzen, Harper Collins, London.

Peacocke, C., 1992, A Study of Concepts, MIT Press, Cambridge, Mass. 
Roberts, C., 2004, "Context in Dynamic Interpretation", in L. Horn and G. Ward 2004, pp. 197-220.

Sosa E., 2015, Judgment and Agency, Oxford University Press, Oxford.

Soteriou, M., 2016, Disjunctivism, Routledge, London.

Stalnaker, R., 1999, Context and Content, Oxford University Press, Oxford.

_- 1999a, "The Problem of Logical Omniscience (II)", in R. Stalnaker 1999.

- 1991 , "The Problem of Logical Omniscience", Synthese, vol. 89, no. 3, pp. 425-440.

, 1984, Inquiry, MIT Press, Cambridge, Mass.

Velleman, J.D., 2000, The Possibility of Practical Reason, Oxford University Press, Oxford.

Walton, K., 1993, Mimesis as Make-Believe: On the Foundations of the Representational Arts, Harvard University Press, Cambridge, Mass.

Yalcin, S., 2018, "Belief as Question Sensitive", Philosophy and Phenomenological Research, vol. 97, no. 1, pp. 23-47.

Received: September 5, 2019; revised: April 9, 2020; accepted: April 24, 2020. 